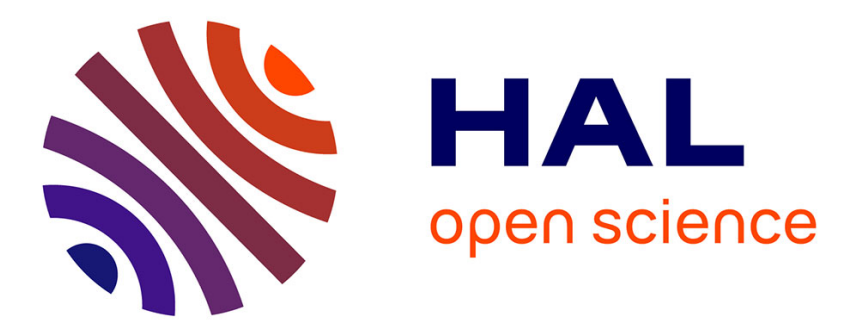

\title{
Simulating compound-specific isotope ratios in plumes of groundwater pollutants with BIOSCREEN-AT-ISO
}

Patrick Höhener, Zhi M Li, Maxime Julien, Pierrick Nun, Richard J. Robins, Gérald S. Remaud

\section{- To cite this version:}

Patrick Höhener, Zhi M Li, Maxime Julien, Pierrick Nun, Richard J. Robins, et al.. Simulating compound-specific isotope ratios in plumes of groundwater pollutants with BIOSCREEN-AT-ISO. Groundwater, 2017, 55 (2), pp.261-267. 10.1111/gwat.12472 . hal-01491099

\section{HAL Id: hal-01491099 \\ https://hal-amu.archives-ouvertes.fr/hal-01491099}

Submitted on 2 May 2018

HAL is a multi-disciplinary open access archive for the deposit and dissemination of scientific research documents, whether they are published or not. The documents may come from teaching and research institutions in France or abroad, or from public or private research centers.
L'archive ouverte pluridisciplinaire HAL, est destinée au dépôt et à la diffusion de documents scientifiques de niveau recherche, publiés ou non, émanant des établissements d'enseignement et de recherche français ou étrangers, des laboratoires publics ou privés. 


\section{Simulating stable isotope ratios in plumes of groundwater pollutants with BIOSCREEN-AT-ISO}

Patrick Höhener ${ }^{1 *}$, Zhi M. Li ${ }^{1}$, Maxime Julien ${ }^{2}$, Pierrick Nun ${ }^{2}$, Richard J. Robins ${ }^{2}$, Gérald S. Remaud ${ }^{2}$

${ }^{1}$ Aix Marseille Univ,-CNRS UMR 7376, Laboratoire Chimie Environnement, 3 place Victor Hugo, F-13331 Marseille, France.

${ }^{2}$ Nantes University, CNRS UMR 6230, EBSI team, CEISAM, 2 rue de la Houssinière, F-44322 Nantes, France.

*Corresponding author: Patrick Höhener, Phone: ++334135510 34; Fax ++334135510 60; e-mail: patrick.hohener@univ-amu.fr

Revised version, GW20160413-0085

Conflict of interest: None. 


\section{Abstract}

2 BIOSCREEN is a well-known simple tool for evaluating the transport of dissolved 3 contaminants in groundwater, ideal for rapid screening and teaching. This work extends the 4 BIOSCREEN model for the calculation of stable isotope ratios in contaminants. A three5 dimensional exact solution of the reactive transport from a patch source, accounting for 6 fractionation by first-order decay and/or sorption, is used. The results match those from a 7 previously published isotope model but are much simpler to obtain. Two different isotopes 8 may be computed, and dual isotope plots can be viewed. The dual isotope assessment is a 9 rapidly emerging new approach for identifying process mechanisms in aquifers. Furthermore, 10 deviations of isotope ratios at specific reactive positions with respect to "bulk" ratios in the 11 whole compound can be simulated. This model is named BIOSCREEN-AT-ISO and will be 12 downloadable from the journal homepage.

\section{Article Impact Statement}

15 This BIOSCREEN-AT decision support system can compute compound- and positionspecific stable isotope ratios in groundwater pollutant plumes.

\section{Keywords}

19 Reactive transport, saturated zone, contaminated sites, natural attenuation, stable isotopes 


\section{Introduction}

21 The BIOSCREEN model had been developed by the US EPA in 1996 (Newell et al. 1996) as a

22 user-friendly simulation tool for the evaluation of the transport of dissolved contaminants in

23 groundwater. Under the name of BIOSCREEN-AT, an improved version based on the exact

24 analytical solution for reactive transport from a patch source in 3 dimensions was later published

25 (Karanovic et al. 2007) and distributed as an MS EXCEL-based spreadsheet. Within the last 15

26 years, considerable progress has been made in the analysis of isotope ratios in dissolved

27 groundwater pollutants. Compound-specific isotope analysis (CSIA) of either ${ }^{13} \mathrm{C},{ }^{2} \mathrm{H}$, or ${ }^{15} \mathrm{~N}$ can

28 be made using isotope ratio monitoring by Mass Spectrometry (irm-MS) (Hofstetter and Berg

29 2007; Elsner 2010; Thullner et al. 2012). This method is able to realize multi-element analyses

30 using a small amount of sample and to determine isotope ratios of mixtures components using

31 Gas Chromatography (GC) or High Performance Liquid Chromatography (HPLC) coupling. The

32 main inconvenient of this method is that it only allows determining the average over the whole

33 molecule isotopic composition, missing the intramolecular distribution of heavy isotopes in the

34 studied compounds. In this context, different methods have been developed in order to perform

35 Position-Specific Isotope Analysis (PSIA). The isotope ratio measurement by ${ }^{13} \mathrm{C}$ Nuclear

36 Magnetic Resonance Spectrometry (irm- ${ }^{13} \mathrm{C}$ NMR) is a recently developed technique capable of

37 determining the isotopic composition of each carbon position of a large panel of molecules

38 (Caytan et al. 2007). In a previous study, irm- ${ }^{13} \mathrm{C}$ NMR has recently proven its interest in the

39 determination of origin of contaminants (Julien et al. 2016) and the study of their remediation

40 (Julien et al. 2015a+b).

41 Changes in isotope ratios during reactive transport are indicative of reactive processes: bond-

42 breaking processes can cause a large isotope fractionation at the position of the initial bond 
43 cleavage, often leading to an enrichment of the remaining non-degraded pollutant.. Smaller 44 secondary isotope fractionation at t sites adjacent to a reactive position can also occur. Also, 45 when the transformation products of pollutants are also components of the primary pollutants in 46 the contamination source, isotope ratio can be used to differentiate the origins of chemicals and 47 provide actual description of reactive processes. Thus, US EPA recommended the use of CSIA to 48 access biodegradation processes and to identify the source of organic groundwater contaminants

49 (Hunkeler et al. 2008). CSIA has been largely applied to study natural attenuation processes in 50 contaminated field investigation like discussed in three critical review articles (Meckenstock et 51 al. 2004; Schmidt et al. 2004; Elsner 2010). To our knowledge, PSIA has not been applied in 52 field investigation but it represents a promoting trend of isotope fractionation pattern for the 53 study of natural attenuation processes in contaminated groundwater.

54 Equilibrium sorption can also create small to intermediate isotope fractionation at certain 55 positions of molecules, but unfortunately the effect also causes in most cases an enrichment of 56 the remaining pollutant (Kopinke et al. 2005; Höhener and Yu 2012), which could be wrongly 57 interpreted as an effect of degradation. In contrast, the physical dilution of compounds should $a$ 58 priori not change isotope ratios (Elsner 2010). In combination, these isotope fractionations can 59 impact on the bulk (average over the whole molecule) isotope ratios observed, but position 60 specific fractionations are inevitably diluted out when only CSIA is exploited. PSIA, in contrast, 61 gives access to the individual values.

62 Because of the high information content of isotope ratios in contaminants in groundwater plumes, 63 they are often measured to obtain a better understanding of natural attenuation processes. 64 Moreover, fractionation factors for a large number of bond-breaking reactions and for 65 equilibrium sorption are available (Aelion et al. 2010; Höhener and Yu 2012). 
66 Analytical or numerical models for compound-specific isotope ratios in aquifer pollutants have

67 been developed. Höhener and Atteia (2010) showed with analytical models on MAPLE

68 worksheets that only the exact analytical solution in BIOSCREEN-AT gives correct isotope

69 ratios at lateral plume margins. However, all current isotope models are quite demanding in

70 operational skills and partly also in CPU time and therefore have not been widely exploited.

71 The present work here combines the know-how of isotope evolution from the more complex

72 models with the well-known and user-friendly model BIOSCREEN-AT to propose a simple tool

73 predicting isotope ratios in groundwater as a function of time and space. The tool should compute

74 two different isotopes in each compound (e.g. ${ }^{13} \mathrm{C}$ and ${ }^{2} \mathrm{H}$ ) in order to create the so-called dual-

75 isotope plots (Vogt et al. 2016). These plots are very sensitive to different reaction mechanisms.

76 The overall goal is that a user can rapidly deduce whether their combined data on concentration

77 and isotope ratios prove unambiguously the degradation and/or sorption of the target pollutant in

78 the studied aquifer.

\section{Analytical solution and its implementation}

80 The schematic representation of the pollution scenario in a homogeneous 3-dimensional aquifer

81 is shown in Figure 1. The aquifer is semi-infinite in the $\mathrm{x}$ direction, and infinite in the $\mathrm{y}$ and $\mathrm{z}$

82 directions. Reactive transport is modeled with the advection-dispersion equation given for the $\mathrm{x}$ -

$83 \mathrm{y}-\mathrm{z}$ space as in equation (1), under the following assumptions: groundwater flow is steady and

84 uni-directional along the $\mathrm{x}$-axis; material properties are homogeneous; partitioning between

85 dissolved and sorbed phases is instantaneous and reversible; neither gas phases nor volatilization

86 from groundwater is modeled; the solute undergoes degradation following first-order kinetics, but

87 only in the dissolved phase (which is realistic for microorganisms which degrade dissolved

88 pollutants at low environmental concentrations). 
$R_{f} \frac{\partial C}{\partial t}=v \alpha_{x} \frac{\partial^{2} C}{\partial x^{2}}+v \alpha_{y} \frac{\partial^{2} C}{\partial y^{2}}+v \alpha_{z} \frac{\partial^{2} C}{\partial z^{2}}-v \frac{\partial C}{\partial x}-\lambda C$

90 In Eq. (1), $v$ is the unretarded groundwater flow velocity $\left(\mathrm{m} \mathrm{yr}^{-1}\right), \alpha_{x}$ is longitudinal dispersivity

91 (m), $\alpha_{y}$, and $\alpha_{z}$ are the transversal dispersivities in the $\mathrm{y}$ (horizontal), and $\mathrm{z}$ (vertical) direction

$92(\mathrm{~m}), \lambda$ is a first-order degradation rate $\left(\mathrm{yr}^{-1}\right)$, and $\mathrm{R}_{\mathrm{f}}$ is the retardation factor (see eq. (4)). We use

93 the exact solution of eq. (1) from Cleary and Ungs (1978) which is equation (2):

$94 C_{i(x, y, z, t)}=C_{0, i} \Omega_{(\lambda i, x, y, z, t)}$

95 with

96

$$
\Omega_{(\lambda i, x, y, z, t)}=\frac{x}{8 \sqrt{\pi \alpha_{x} v^{\prime}}} \exp \left(-\gamma\left(t-\frac{x}{v^{\prime}}\right)\right) \int_{0}^{t} \frac{1}{\tau^{1.5}} \exp \left[-\frac{\lambda_{i}}{R_{f, i}} \tau-\frac{x^{2}}{4 v^{\prime} \alpha_{x} \tau}\right]
$$

$$
\left.\left\{\operatorname{erfc}\left[\frac{y-0.5 Y}{2 \sqrt{\alpha_{y} v^{\prime} \tau}}\right]-\operatorname{erfc}\left[\frac{y+0.5 Y}{2 \sqrt{\alpha_{y} v^{\prime} \tau}}\right]\right\} \operatorname{erfc}\left[\frac{z-Z}{2 \sqrt{\alpha_{y} v^{\prime} \tau}}\right]-\operatorname{erfc}\left[\frac{z+Z}{2 \sqrt{\alpha_{y} v^{\prime} \tau}}\right]\right\} d \tau
$$

and where $\mathrm{i}$ stands for a specific isotope, $\gamma$ is a first-order decay rate of the concentration in the

source, $v^{\prime}=v / R_{f, i}$, and $C_{0, i}$ is the (constant) concentration of isotope $i$ in the source $\left(\mathrm{mol} \mathrm{L}^{-1}\right)$.

The use of the exact solution fixes problems associated with the first BIOSCREEN model which was based on Domenico's analytical solution. This issue was broadly discussed in several publications (Guyonnet and Neville 2004; Srinivasan 2007; West et al. 2007).

105 For isotope modeling, we use the isotope approach (Hunkeler et al. 2009; Höhener and Atteia 2010) where each isotope is modeled separately. Light (l) and heavy (h) isotopes are modeled using different $\lambda$ caused by kinetic isotope fractionation during bond cleavage (fractionation

108 factor $\left.\alpha_{\text {react}}\right)$, and using different $R_{f, i}$ caused by equilibrium isotope effects by sorption

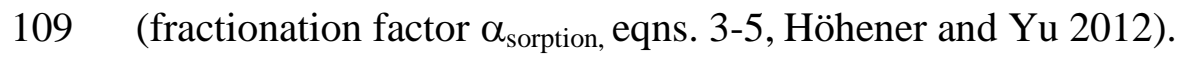

$110{ }^{l} \lambda=\lambda$ 
$11{ }^{h} \lambda=\lambda \alpha_{\text {react }}$

$112{ }^{l} R_{f}=1+\frac{\rho_{b}}{n} f_{O C} K_{O C}$

$113{ }^{h} R_{f}=1+\frac{\rho_{b}}{n} f_{O C} K_{O C} \alpha_{\text {sorption }}$

$114{ }^{l} C_{0}=C_{0} /\left(1+R_{0}\right)$

$115{ }^{h} C_{0}=C_{0} R_{0} /\left(1+R_{0}\right)$

116 Here, $\rho_{\mathrm{b}}$ is the soil bulk density $\left(\mathrm{kg} \mathrm{L}^{-1}\right), \mathrm{n}$ is effective porosity, $\mathrm{K}_{\mathrm{OC}}$ is the partitioning coefficient

117 of the contaminant between organic carbon and water $\left(\mathrm{L} \mathrm{kg}^{-1}\right), f_{O C}$ is the unitless fraction of 118 organic carbon of the aquifer solids, and $\mathrm{R}_{0}$ is the initial (constant) isotope ratio of the

119 contaminant in the source. Equations 3 and 4 create different transport behavior of light and

120 heavy isotopes, which finally lead to changes in the isotope ratios.

121 These isotope ratios in delta notation (in \%o) are finally obtained by equation (6):

$122 \delta_{(x, y, z, t)}=\left(\frac{\left[\frac{{ }^{h} C_{(x, y, z, t)}}{{ }^{l} C_{(x, y, z, t)}}\right]}{R_{\text {standard }}}-1\right) 1000$

123 where $\mathrm{R}_{\text {standard }}$ is the isotope ratio of the international standard for the element of interest.

124 For the purpose of the assessment of degradation, equation (7), which computes the percent of 125 degradation $\mathrm{B}(\%)$ compared to overall concentration decrease in the contaminant, was 126 incorporated into the model:

$128 \mathrm{~B}(\%)$ is mainly caused by biotic reaction, but at some sites also abiotic reactions were found to

129 fractionate isotopes. The equation 7 is only valid when the change in isotope ratios is uniquely 
130 caused by reaction. In cases where sorption fractionates isotopes, the B (\%) will be wrong. This is

131 illustrated in the spreadsheet because the model gives also the true B (\%) obtained from modeling 132 a sorption-affected tracer and equation (8).

$$
B(\%)_{\text {true }}=100\left(1-\frac{C_{\text {compound }} / C_{\text {compoundsource }}}{C_{\text {tracer }} / C_{\text {tracer,source }}}\right)
$$

134 Here, $\mathrm{C}_{\text {tracer }}$ is a simulated concentration of a sorbing tracer affected by $\mathrm{R}_{\mathrm{f}}$. The equations were

135 implemented on a spreadsheet (MS EXCEL, version 2010). The integration of the $\Omega$ factors of

136 equation (1) is made in 100 steps of $\mathrm{d} \tau$. In order to test the exactness of the approach

137 implemented in EXCEL, the results were compared to numerical integrations made by MAPLE

138 (version 13, Waterloo Maple Inc, Waterloo, Canada) using the Maple worksheet from Höhener

139 and Atteia (2010) with the exact solution of Wexler (1992).

\section{Example calculations}

141 The presented example here is for methyl tert-butyl ether (MTBE). Fractionation factors of ${ }^{13} \mathrm{C}$

142 and ${ }^{2} \mathrm{H}$ during aerobic degradation were chosen as similar to those found in laboratory 143 experiments (Rosell et al. 2007). MTBE has an intra-molecular variation in ${ }^{13} \mathrm{C}$ isotope ratio, with 144 the methyl group (in the NMR spectrum position 2 according to the chemical shift) being most 145 negative (Julien et al. 2016). Initial enzymatic attack will occur at this position, leading to the

146 largest isotope fractionation at this $\mathrm{C}$ atom. Two scenarios were modeled (see Table 1 for model 147 parameters). Scenario 1 presents an old plume in groundwater with low flow velocity, without 148 any sorption, whereas scenario 2 is a young plume in a faster flowing groundwater where 149 sorption occurs and sorption fractionates the pollutant in addition to the fractionation by 150 degradation. Both scenarios were modeled with the present model (BIOSCREEN-AT-ISO) and 151 the MAPLE model (Höhener and Atteia 2010). The results are shown in Figures 2 and 3. 
152 Figures $2 \mathrm{a}$ and $3 \mathrm{a}$ show that concentrations along the plume centerline both match exactly the

153 concentrations modeled by the MAPLE worksheet, indicating that the integration of time in the

154 EXCEL model in 100 steps is sufficiently accurate compared to an independent numerical

155 integration both for short and long times ( 2 and 50 years). The other subsets in Figures 2 and 3

156 show that both models also yield identical results for isotope ratios of ${ }^{13} \mathrm{C}$ and of ${ }^{2} \mathrm{H}$. The

157 modeled curves along the plume centerline indicate that the isotope data enable a clear distinction

158 between scenario 1, wherein only degradation fractionates, and scenario 2, wherein sorption also

159 contributes to fractionation. The increases of the ratios are enhanced in scenario 2, especially at

160 the forerunning plume front. The explanation for this is that only at the fore-running front of

161 young plumes, there are sorption sites unoccupied by the contaminant, and therefore fractionation

162 can occur when the contaminant sorbs to these sites. Near the source, or everywhere in old

163 plumes, sorption sites are already occupied by contaminant, and no fractionation occurs anymore.

164 This had previously been predicted (Kopinke et al. 2005). Figures 2c and 3c show that the slope

$165 \Lambda$ in the dual isotope plots $\Delta \delta^{2} \mathrm{H}$ vs $\Delta \delta^{13} \mathrm{C}$ does not lie exactly on the approximation $\Lambda \approx$

$166 \varepsilon \mathrm{H} / \varepsilon \mathrm{C} \approx 15$ in both cases, and that the present model is a helpful tool to investigate why and how

167 such slopes change as a function of two fractionating processes and of dispersion. It had been

168 shown previously that dispersion must be taken into account for the interpretation of field isotope

169 data, even when dispersion itself does not create fractionation (Abe and Hunkeler 2006). Finally,

170 Figures $2 \mathrm{~b}$ and $3 \mathrm{~b}$ show in addition that, for the carbon isotope ratios, a position-specific isotope

171 measurement of $\delta^{13} \mathrm{C}$ would enhance even more the discriminatory power of the isotope

172 approach, since the $\delta^{13} \mathrm{C}$ in the reactive position 2 increases by up to $10 \%$, whereas the bulk $\delta^{13} \mathrm{C}$

173 increases only by $2 \%$. Once progress is made in the purification of samples in order to perform 
174 PSIA by NMR (Julien et al. 2015) in real-world groundwater, our model is operational for data

175 interpretation.

\section{Conclusions}

177 To sum up, the BIOSCREEN-AT-ISO model with stable isotopes is validated in this work and

178 can serve in future as a tool for isotope geochemists for the assessment of natural attenuation of

179 dissolved groundwater pollutants during reactive transport. The BIOSCREEN-AT format was

180 chosen because it gained popularity in the community of groundwater remediation and proved to

181 be useful for rapid assessment and teaching. The study of field processes using compound-

182 specific isotope analysis is recommended by US EPA which published guidelines for isotope data

183 interpretations (Hunkeler et al. 2008). Field data of concentrations and isotope ratios are easily

184 assessed with the model, and the contribution of biodegradation to natural attenuation can be

185 quantified at any point in the aquifer. The model predicts dual isotope evolutions in space and

186 time and reinforces interpretations of degradation mechanisms (Vogt et al. 2016). The model is

187 an ideal complement to more sophisticated numerical models: this analytical model is free of

188 numerical dispersion and can be used to validate results from numerical codes for homogeneous

189 cases. More sophisticated numerical approaches would need very time-consuming tailor-made

190 modeling and maybe development of codes, while the use of a spreadsheet model like

191 BIOSCREE-AT-ISO can simulate in some hours a three-dimensional field case and can check

192 whether an investment in more complex models is worthwhile. The limitations of this model

193 compared to numerical approaches are: 1) it is only valid only in homogeneous systems; 2) only

194 for constant or experimentally decaying sources; 3) only for linear sorption isotherms; and 4)

195 only for stable isotopes of $\mathrm{C}, \mathrm{H}, \mathrm{N}$, and $\mathrm{O}$, but not for $\mathrm{Cl}$ which behaves differently (Hunkeler et 
196 al. 2009). The BIOSCREEN-AT-ISO is a Microsoft EXCEL spreadsheet compatible with

197 versions 2010 or later and can be downloaded free of charge from the Journal website.

\section{Acknowledgments}

199 This work was funded by the French National Research Agency ANR, project ISOTO-POL

200 funded by the program CESA ( ${ }^{\circ} 009$ 01). M. Julien thanks the ANR for funding his PhD

201 bursary through this project. We thank three unknown reviewers for their helpful comments.

\section{Supplementary Material}

204 The following supplementary material is available for this article: EXCEL Spreadsheets

205 containing the model and the example calculations of scenarios $1+2$. 


\section{References}

Abe, Y. and D. Hunkeler. 2006. Does the Rayleigh equation apply to evaluate field isotope data in contaminant hydrogeology? Environmental Science \& Technology 40, no. 5: 15881596.

Aelion, C.M. P. Höhener, D. Hunkeler and R. Aravena. 2010. Environmental Isotopes in Biodegradation and Bioremediation. Boca Raton: CRC Press (Taylor and Francis).

Caytan, E. G.S. Remaud, E. Tenailleau and S. Akoka, 2007. Precise and accurate quantitative C13 NMR with reduced experimental time. Talanta 71, no. 3: 1016-1021.

Cleary, R.W. and M.J. Ungs. 1978. Analytical models for ground water pollution and hydrology, Princeton University, Water, Resources Program Report 78-WR-15.

Elsner, M. 2010. Stable isotope fractionation to investigate natural transformation mechanisms of organic contaminants: principles, prospects and limitations. Journal of Environmental Monitoring 12, no. 11: 2005-2031.

Hunkeler, D. R.U. Meckenstock, B. Sherwood Lollar, T.C. Schmidt and J.T. Wilson, 2008. A Guide for Assessing Biodegradation and Source Identification of Organic Ground Water Contaminants using Compound Specific Isotope Analysis (CSIA), US EPA, Office of Research and Development National Risk Management Research Laboratory,, Ada, Oklahoma 74820.

Guyonnet, D. and C. Neville, 2004. Dimensionless analysis of two analytical solutions for 3-D solute transport in groundwater. J. Cont. Hydrol. 75, no. 141-153.

Hofstetter, T. B. and Berg, M. 2011. Assessing transformation processes of organic contaminants by Compound-Specific Stable Isotope Analysis. TrAC, 30, 618-627.

Höhener, P. and O. Atteia. 2010. Multidimensional analytical models for isotope ratios in ground water pollutant plumes of organic contaminants undergoing different biodegradation kinetics. Advances in Water Resources 33, no. 740-51.

Höhener, P. and X. Yu. 2012. Stable carbon and hydrogen isotope fractionation of dissolved organic ground water pollutants by equilibrium sorption. Journal of Contaminant Hydrology 129/130, no. 54-61.

Hunkeler, D. B.M. Van Breukelen and M. Elsner. 2009. Modeling chlorine isotope trends during sequential transformation of chlorinated ethenes. Environmental Science \& Technology 43, no. 17: 6750-6756.

Julien, M. P. Nun, J. Parinet, P. Höhener, R.J. Robins and G.S. Remaud. 2016. Enhanced forensic discrimination of pollutants by position-specific isotope analysis using isotope ratio monitoring by ${ }^{13} \mathrm{C}$ nuclear magnetic resonance spectrometry. Talanta 147, 383-389.

Julien, M. J. Parinet, P. Nun, K. Bayle, P. Höhener, R.J. Robins and G.S. Remaud, 2015a. Fractionation in position-specific isotope composition during vaporization of environmental pollutants measured with isotope ratio monitoring by $13 \mathrm{C}$ nuclear magnetic resonance spectrometry. Environmental Pollution 205, 299-306.

Julien, M. J. Parinet, P. Nun, K. Bayle, P. Höhener, R.J. Robins and G.S. Remaud. 2015 b. Fractionation in position-specific isotope composition during vaporization of environmental pollutants measured with isotope ratio monitoring by $13 \mathrm{C}$ nuclear magnetic resonance spectrometry. Environmental Pollution 205, no. 299-306.

Karanovic, M. C.J. Neville and C.B. Andrews. 2007. BIOSCREEN-AT: BIOSCREEN with an exact analytical solution. Groundwater 45, no. 2: 242-245. 
Kopinke, F.D. A. Georgi, M. Voskamp and H.H. Richnow. 2005. Carbon isotope fractionation of organic contaminants due to retardation on humic substances: Implications for natural attenuation studies in aquifers. Environmental Science \& Technology 39, no. 16: 60526062.

Meckenstock, R.U. B. Morasch, C. Griebler and H.H. Richnow, 2004. Stable isotope factionation analysis as a tool to monitor biodegradation in contaminated aquifers. J. Cont. Hydrol. 75, no. 215-255.

Newell, C. R.K. McLeod and J.R. Gonzales. 1996. BIOSCREEN Natural Attenuation Decision Support System, User's manual, Version 1.3 EPA/600/R-96/087, EPA Office of Research and Development, Washington DC.

Rosell, M. D. Barcelo, T. Rohwerder, U. Breuer, M. Gehre and H.H. Richnow. 2007. Variations in $\mathrm{C}-13 / \mathrm{C}-12$ and $\mathrm{D} / \mathrm{H}$ enrichment factors of aerobic bacterial fuel oxygenate degradation. Environmental Science \& Technology 41, no. 6: 2036-2043.

Schmidt T.C. L. Zwank, M. Elsner, M. Berg, R.U. Meckenstock and S.B. Haderlein. 2004. Compound-specific stable isotope analysis of organic contaminants in natural environments: a critical review of the state of the art, prospects, and future challenges. Analytical and Bioanalytical Chemistry, no. 378: 283-300.

Srinivasan, V. T.P. Clement and K.K. Lee, 2007. Domenico solution - Is it valid? Ground Water 45, no. 2: 136-146.

Thullner, M. F. Centler, H.H. Richnow and A. Fischer, 2012. Quantification of organic pollutant degradation in contaminated aquifers using compound specific stable isotope analysis Review of recent developments. Organic Geochemistry 42, no. 12: 1440-1460.

Vogt, C., C. Dorer, F. Musat and H.H. Richnow, 2016. Multi-element isotope fractionation concepts to characterize the biodegradation of hydrocarbons - from enzymes to the environment. Current Opinion in Biotechnology 41, no. 90-98.

West, M.R. B.H. Kueper and M.J. Ungs, 2007. On the use and error of approximation in the Domenico (1987) solution. Ground Water 45, no. 2: 126-135.

Wexler, E. 1992. Analytical solutions for one-, two, and three-dimensional solute transport in ground water systems with uniform flow. Techniques of Water Resources Investigations of the United States Geological Survey, Chapter B-7, Book 3, Applications of Hydraulics. $79 \mathrm{pp}$. 
Table 1: Aquifer and compound properties used for modeling isotope fractionation in the groundwater plumes with equation (1).

\begin{tabular}{|c|c|c|c|c|}
\hline $\begin{array}{l}\text { Aquifer } \\
\text { Parameters }\end{array}$ & Notation & Unit & $\begin{array}{c}\text { Value } \\
\text { Scenario } 1\end{array}$ & $\begin{array}{c}\text { Value } \\
\text { Scenario } 2\end{array}$ \\
\hline $\begin{array}{l}\text { Groundwater } \\
\text { flow velocity }\end{array}$ & $\mathrm{v}$ & $\mathrm{m} \mathrm{yr}^{-1}$ & 180 & 365 \\
\hline $\begin{array}{l}\text { Longitudinal } \\
\text { dispersivity }\end{array}$ & $\alpha_{x}$ & $\mathrm{~m}$ & 10 & 10 \\
\hline $\begin{array}{l}\text { Transversal } \\
\text { dispersivities }\end{array}$ & $\begin{array}{l}\alpha_{y} \\
\alpha_{z}\end{array}$ & $\begin{array}{l}\mathrm{m} \\
\mathrm{m}\end{array}$ & $\begin{array}{c}1 \\
0.1\end{array}$ & $\begin{array}{c}1 \\
0.1\end{array}$ \\
\hline $\begin{array}{l}\text { Ratio of solids to } \\
\text { water }\end{array}$ & $\mathrm{r}_{\mathrm{sw}}$ & $\mathrm{kg} \mathrm{L}^{-1}$ & 5 & 5 \\
\hline $\begin{array}{l}\text { Organic carbon } \\
\text { content }\end{array}$ & $f_{O C}$ & $\mathrm{~kg}^{-1} \mathrm{~kg}^{-1 C}$ & 0 & 0.05 \\
\hline $\begin{array}{l}\text { Source width and } \\
\text { depth }\end{array}$ & $\begin{array}{l}\mathrm{Y} \\
\mathrm{Z}\end{array}$ & $\mathrm{m}$ & $\begin{array}{c}20 \\
\text { infinite }\end{array}$ & $\begin{array}{c}20 \\
\text { infinite }\end{array}$ \\
\hline $\begin{array}{l}\text { Compound } \\
\text { parameters }\end{array}$ & MTBE & & & \\
\hline $\begin{array}{l}\text { Concentration of } \\
\text { MTBE }\end{array}$ & $\mathrm{C}_{0}$ & $\mathrm{mM}$ & 1 & 1 \\
\hline $\begin{array}{l}\text { Org. carbon-water } \\
\text { part. coefficient }\end{array}$ & $\mathrm{K}_{\mathrm{OC}}$ & $\mathrm{L} \mathrm{kg}_{\mathrm{OC}}{ }^{-1}$ & 12 & 12 \\
\hline Retardation factor & $\mathrm{R}_{\mathrm{f}}$ & $(-)$ & 1 & 5.8 \\
\hline $\begin{array}{l}\text { Carbon } \\
\text { enrichment factor } \\
\text { for degradation } \\
\text { for sorption }\end{array}$ & $\begin{array}{l}\varepsilon_{\text {react.-bulk }}^{\mathrm{C}} \\
\varepsilon^{\mathrm{C}} \text { react.-pos1/2/3 } \\
\varepsilon^{\mathrm{C}}{ }_{\text {sorption }} \\
\varepsilon^{\mathrm{C}}{ }_{\text {sorp.-pos } 1 / 2 / 3}\end{array}$ & $\begin{array}{l}(\%) \\
(\%) \\
(\%) \\
(\%)\end{array}$ & $\begin{array}{c}-2 \\
0 /-10 / 0 \\
\text { na } \\
\text { na }\end{array}$ & $\begin{array}{c}-2 \\
0 /-10 / 0 \\
-0.3 \\
0 / 0 /-0.5\end{array}$ \\
\hline $\begin{array}{l}\text { Hydrogen } \\
\text { enrichment factor } \\
\text { for degradation } \\
\text { for sorption }\end{array}$ & $\begin{array}{c}\varepsilon_{\text {react.-bulk }}^{\mathrm{H}} \\
\varepsilon_{\text {sorption }}^{\mathrm{H}}\end{array}$ & $\begin{array}{l}(\%) \\
(\%)\end{array}$ & $\begin{array}{c}-30 \\
\text { na }\end{array}$ & $\begin{array}{l}-30 \\
-5\end{array}$ \\
\hline $\begin{array}{l}\text { Initial isotope } \\
\text { ratio }\end{array}$ & $\begin{array}{c}\delta^{13} \mathrm{C}_{0 \text { bulk }} \\
\delta^{13} \mathrm{C}_{0 \text { pos } 1 / 2 / 3} \\
\delta^{2} \mathrm{H}_{0}\end{array}$ & $\begin{array}{l}(\%) \\
(\%) \\
(\%)\end{array}$ & $\begin{array}{c}-29 \\
-17 /-40 /-29 \\
-95\end{array}$ & $\begin{array}{c}-29 \\
-17 /-40 /-29 \\
-95\end{array}$ \\
\hline Degradation rate & $\lambda$ & $\mathrm{yr}^{-1}$ & 1.4 & 1.4 \\
\hline Source decay rate & $\gamma$ & $\mathrm{yr}^{-1}$ & 0 & 0 \\
\hline
\end{tabular}

na: not applicable 


\section{FIGURE CAPTIONS}

Fig. 1: Illustration of pollution scenario setting in $x-y-z$ coordinate system in the modeled aquifer.

Fig. 2: Results from BIOSCREEN-AT-ISO (this work) compared to results from MAPLE models for the scenario 1: a) concentrations, b) isotope ratios, and c) dual isotope evolution, with linear regression of slope $\Lambda$.

Fig. 3: Results from BIOSCREEN-AT-ISO (this work) compared to results from MAPLE models for the scenario 2: a) concentrations, b) isotope ratios, and c) dual isotope evolution, with linear regression of slope $\Lambda$. 


\section{Figure 1:}

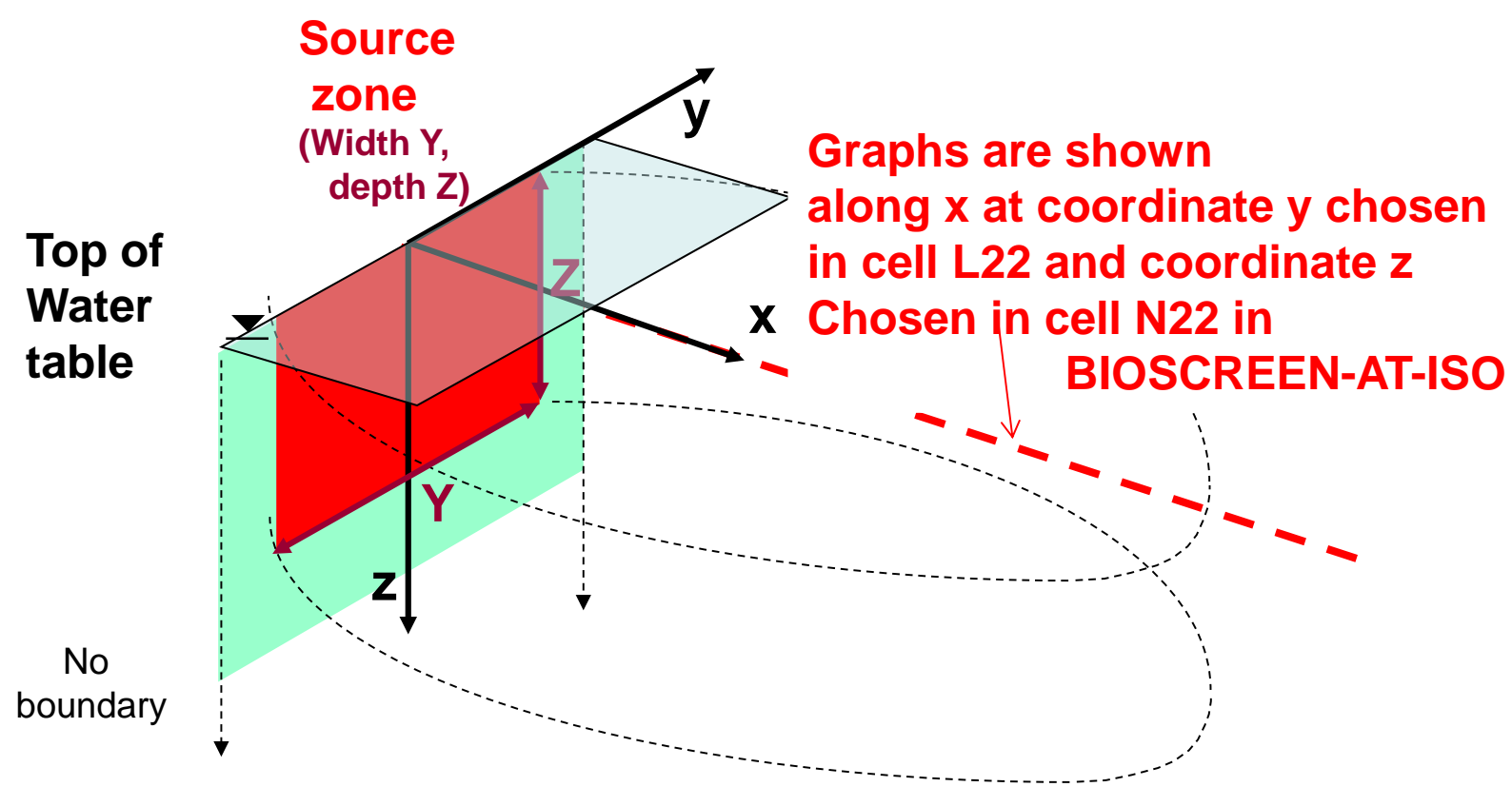


Figures 2 and 3:
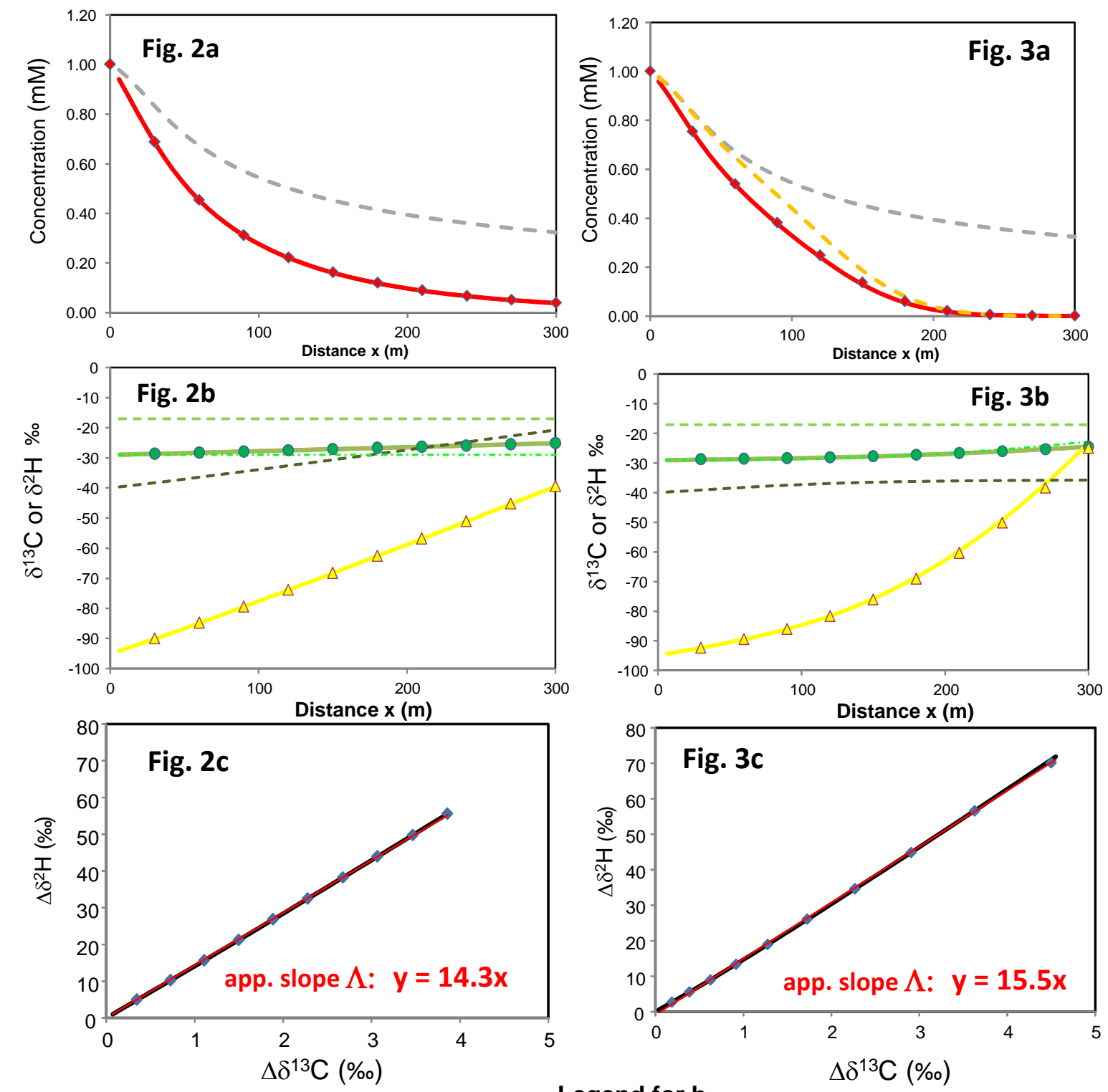

Legend for $b$

Legend for a

- MTBE, MAPLE
- MTBE, BIOSCREEN-AT-ISO
$-\quad$ non-reactive Tracer
$-\quad$ sorbing Tracer

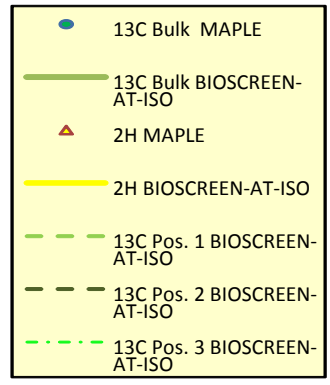

Legend for $\mathrm{C}$

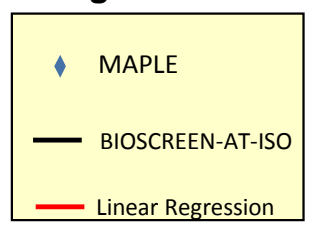

